$11-2009$

\title{
A pilot study evaluating the safety of vaginal administration of a multi-particulate pellet formulation
}

Guido Lopes dos Santos Santiago 
Provided for non-commercial research and education use. Not for reproduction, distribution or commercial use.

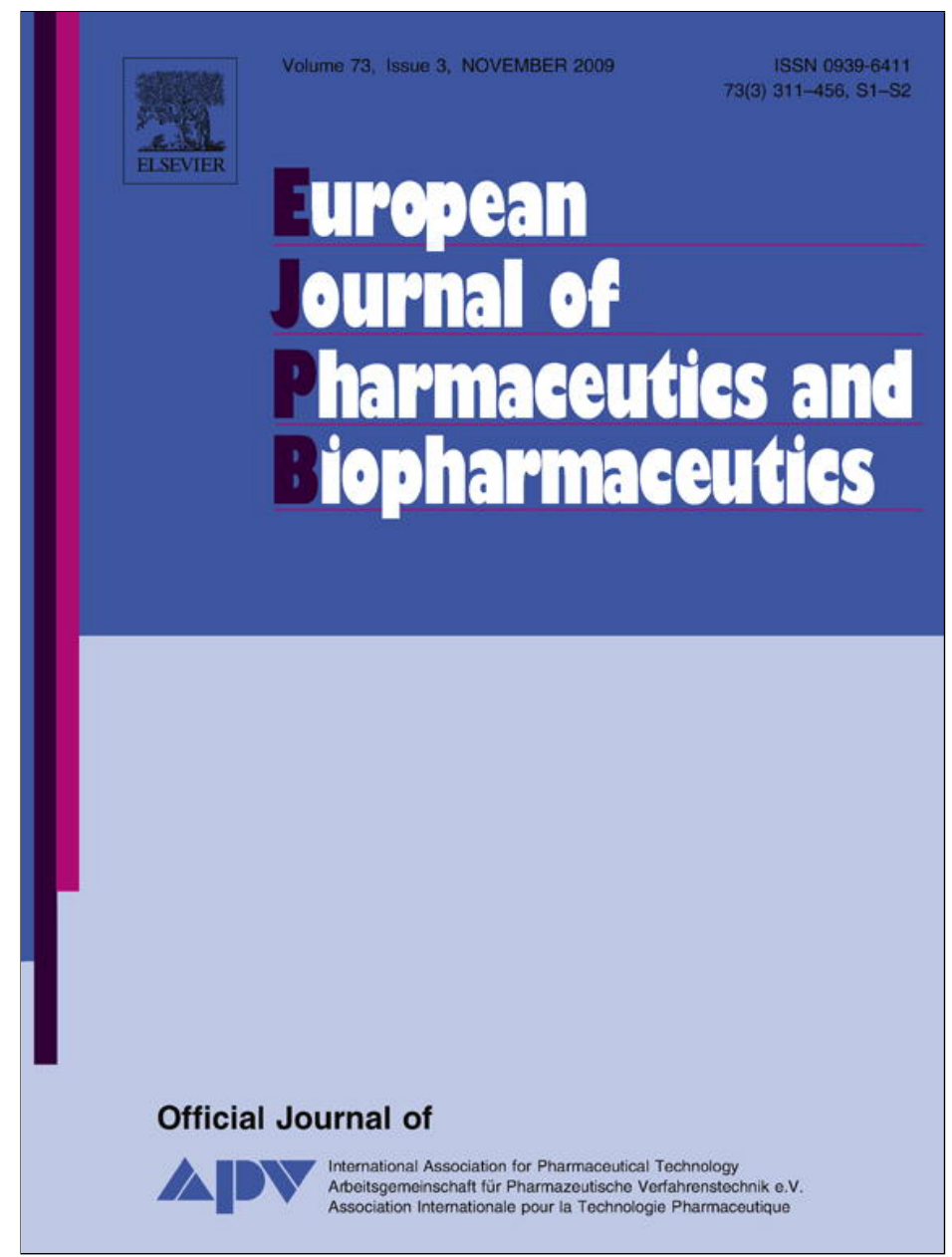

This article appeared in a journal published by Elsevier. The attached copy is furnished to the author for internal non-commercial research and education use, including for instruction at the authors institution and sharing with colleagues.

Other uses, including reproduction and distribution, or selling or licensing copies, or posting to personal, institutional or third party websites are prohibited.

In most cases authors are permitted to post their version of the article (e.g. in Word or Tex form) to their personal website or institutional repository. Authors requiring further information regarding Elsevier's archiving and manuscript policies are encouraged to visit:

http://www.elsevier.com/copyright 
Research paper

\section{A pilot study evaluating the safety of vaginal administration of a multi-particulate pellet formulation}

\section{Guido Lopes dos Santos Santiago ${ }^{a}$, Hans Verstraelen ${ }^{b}$, Nele Poelvoorde ${ }^{c, d}$, Steven De Corte ${ }^{\mathrm{e}}$, Geert Claeys ${ }^{\mathrm{f}}$, Marijke Trog $^{\mathrm{b}}$, Ellen De Backer ${ }^{\mathrm{a}}$, Bart Saerens ${ }^{\mathrm{a}}$, Chris Vervaet ${ }^{\mathrm{c}, \mathrm{d}}$, Fabienne De Boeck ${ }^{\mathrm{e}}$, Lucas Van Bortel ${ }^{\mathrm{e}}$, Jean-Paul Remon ${ }^{\mathrm{c}, \mathrm{d}}$, Marleen Temmerman ${ }^{\mathrm{b}}$, Mario Vaneechoutte ${ }^{\mathrm{a}}$, Rita Verhelst ${ }^{\mathrm{a}, *}$}

a Laboratory of Bacteriology Research (LBR), Ghent University, Ghent, Belgium

${ }^{\mathrm{b}}$ Department of Obstetrics and Gynaecology, Ghent University Hospital, Ghent, Belgium

${ }^{\mathrm{c}}$ Laboratory of Pharmaceutical Technology, Ghent University, Ghent, Belgium

${ }^{\mathrm{d}}$ Heymans Institute of Pharmacology, Ghent University, Ghent, Belgium

${ }^{\mathrm{e}}$ Drug Research Unit Ghent, Ghent University Hospital, Ghent, Belgium

${ }_{\mathrm{f}}^{\mathrm{f}}$ Laboratory Clinical Biology, Ghent University Hospital, Ghent, Belgium

\section{A R T I C L E I N F O}

\section{Article history:}

Received 26 May 2009

Accepted in revised form 31 August 2009

Available online 4 September 2009

\section{Keywords:}

Probiotics

Starch

Pellet

Vaginal delivery

Bacterial vaginosis

\begin{abstract}
A B S T R A C $T$
Aim: Quantitative evaluation of the effect caused by vaginal administration of gelatin capsules loaded with starch pellets and lyophilized powder, respectively, on vaginal $\mathrm{pH}$ and microflora.

Method: Administration of gelatin capsules loaded with fast-disintegrating starch pellets (group P) or lyophilized lactose/skimmed milk (group L) was compared to no intervention (group C) in a 3-way randomized, double-blinded, parallel study with 18 volunteers. Follow-up visits were at day 6 (immediately after administration), day 14 (pill stop), day 22 (after withdrawal bleeding) and day 35 (midcycle). Vaginal $\mathrm{pH}$ was measured and swabs were taken for Gram staining and culture to assess the presence of hydrogen peroxide-producing lactobacilli. Colposcopy was performed to assess the occurrence of adverse effects on the vaginal and ectocervical mucosa.

Results: No severe adverse events occurred. For all women, vaginal pH and Gram stain were normal from screening until pill stop. Although immediately after withdrawal bleeding, 8 out of 18 women had an elevated $\mathrm{pH}$, a disturbed microflora or lacked hydrogen peroxide-producing lactobacilli, all women had hydrogen peroxide-producing lactobacilli and a normal vaginal $\mathrm{pH}$ at midcycle, and all but two had a normal Gram stain.

Conclusion: No major differences could be observed between the groups, whereby all changes in $\mathrm{pH}$ and microflora could be ascribed to withdrawal bleeding, indicating that gelatin capsules, starch pellets and lyophilized powder are acceptable carrier materials for the vaginal delivery of probiotic strains.
\end{abstract}

(C) 2009 Elsevier B.V. All rights reserved.

\section{Introduction}

Bacterial vaginosis (BV), a condition whereby hydrogen peroxide $\left(\mathrm{H}_{2} \mathrm{O}_{2}\right)$-producing lactobacilli are overgrown by anaerobic bacteria, is the most common etiology of vaginal symptoms prompting women to seek medical care and confers an increased risk of preterm delivery in pregnant women [1,2]. While currently available antibiotic treatments establish short-term symptomatic improvement but do not prevent high rates of recurrence of BV; exogenous supplementation of vaginal lactobacilli could restore the vaginal microflora $[3,4]$.

\footnotetext{
* Corresponding author. Laboratory of Bacteriology Research, Ghent University, De Pintelaan 185, 9000 Ghent, Belgium. Tel.: +32 933236 92; fax: +32 93323659. E-mail address: Rita.Verhelst@UGent.be (R. Verhelst).
}

An optimal formulation for vaginal delivery of probiotic strains should (1) have a long retention time to maximize release of the probiotic strain, (2) have a proper spreading over the vaginal vault to establish colonization of the probiotic strain on different sites of the vaginal tract, (3) not cause harm to the normal vaginal microflora and mucosa, (4) be easy to administer and (5) not cause discomfort to the patient.

Different types of formulations for delivery of vaginal probiotics are commercially available, but the main group of vaginal probiotic delivery forms is lyophilized powders compacted into tablets and lyophilized powders with a gelatin-based encapsulation. Also tampons impregnated with lactobacilli are commercially available.

Probiotic strains are always used in combination with other synergistically acting and stabilizing ingredients. The probiotic formula can be improved by using the right bioadhesive (e.g. gelatin or hydroxyl propyl methyl cellulose) and carrier (e.g. starch), by 
adding energy sources (e.g. glucose), prebiotics (e.g. lactitol), vitamins (e.g. ascorbic acid), freeze dry protectants and preservatives (e.g. lactose), tablet stabilizers (e.g. magnesium stearate), essential fatty acids (e.g. alpha linoleic acid) and trace elements (e.g. selenium) [5]. Several other classes of synergistically acting compounds have been used.

In a previous study, we found starch-based pellets to be a promising new vaginal delivery form, considering the more efficient distribution and longer retention time in the vagina compared to lyophilized powder [6]. It is expected that this new delivery form will enhance the colonization potential of vaginal probiotic strains, leading to a healthier vaginal microflora. The main purpose of this prospective study was to assess whether addition of the carrier material itself does not disrupt the natural protective microflora in the vagina. Both starch-based pellets and lyophilized lactose/ skimmed milk (lyophilized powder) were tested as carriers for vaginal probiotic bacteria. A non-treated control group was included to follow the natural evolution of $\mathrm{pH}$ and microflora during the menstrual cycle.

\section{Materials and methods}

\subsection{Subjects}

We recruited premenopausal non-pregnant women aged 18-50 years with a presumed healthy vaginal microflora and on monophasic pills. Exclusion criteria were history of vaginal surgery and hysterectomy, diagnosed pubis dysfunction, reoccurring vaginal infections ( $<1$ year), active vaginal infections, vulval or vaginal active dermatological aberrations, anamneses of breakthrough bleeding while using oral contraceptives, use of hormone- or copper-releasing IUDs, use of vaginal anticonceptives, i.e. NuvaRing, sexual contact of any kind $48 \mathrm{~h}$ before the screening, use of local or systemic antibiotics, including antimycotics and antiprotozoals, from 3 weeks before the start of the study and for the course of the study. Testing for Chlamydia trachomatis by DNA amplification was done at the baseline visit (Abbott RealTime CT, Abbott Laboratories, Illinois, US) on an endocervical swab specimen. Subjects who tested positive for $C$. trachomatis were excluded.

This study was approved by the research ethics committee (EC UZG 2008/114) of Ghent University Hospital, Belgium.

\subsection{Study design}

After oral and written informed consent, 18 volunteers were randomized, in a double-blinded fashion, into three different groups of six subjects. The first group had to vaginally administer a gelatin capsule loaded with disintegrating starch pellets, without probiotics, for 5 days. The second group had to vaginally administer a gelatin capsule loaded with lyophilized lactose/skimmed milk (ratio $1 / 2$ ) powder, without probiotics, for 5 days. The third group had no intervention. All women were on oral contraception (OC) confined to monophasic combination pills and were instructed to continue OC use until day 14 and then to reinitiate OC use on day 22.

The three groups returned for a gynecological control visit on four separate, well-defined days, i.e. on day 6 , the first day after the last vaginal administration, on day 14 at pill stop, at the end of the withdrawal bleeding on day 22 , and on day 35 , at the midcycle of the next pill cycle. At each follow-up visit, a standard gynecological examination including colposcopy was performed. Evaluation of the vaginal and cervical mucosa through colposcopy was performed according to the CONRAD/WHO guidelines for the evaluation of vaginal products. On each visit, a vaginal swab (Eswab, Copan, Brescia, Italy) was taken and pH was measured with a pH test strip (Macherey-Nagel, Düren, Germany). Subjects were instructed to record in a diary any symptoms or complaints occurring throughout the study period.

\subsection{Vaginal formulations}

The multi-particulate starch-based pellets were produced by extrusion/spheronisation. Dry mixing was performed in a Turbula ${ }^{\circledR}$ mixer (model T 2A, W.A. Bachofen, Basel, Switzerland) for $15 \mathrm{~min}$. The powder mixture was granulated with demineralised water for 10 min using a planetary mixer (Kenwood Chief, Hampshire, UK) with a K-shaped mixing arm. Water was added during the first $30 \mathrm{~s}$ of the wet massing phase. To ensure uniform water distribution, the material adhering to the mixing bowl was regularly removed. The wet mass was extruded at an extrusion speed of $50 \mathrm{rpm}$ using a single screw extruder (Dome extruder lab model DG-L1, Fuji Paudal, Tokyo, Japan) equipped with a dome-shaped extrusion screen with $0.4 \mathrm{~mm}$ perforations. The extrudates were spheronised in a spheroniser having a friction plate with crosshatched geometry (Caleva Model 15, Caleva, Sturminster Newton, Dorset, UK). Spheronisation time was $3 \mathrm{~min}$ and spheronisation speed was $1000 \mathrm{rpm}$. The pellets were dried overnight in an oven (Memmert, Schwabach, Germany) at $40{ }^{\circ} \mathrm{C}$.

Gelatin capsules (size 00, Nova, Belgica T.O.P. nv, Turnhout, Belgium) were administered via a commercially available applicator (Infemin applicator, Pierre Fabre santé Benelux, Brussels, Belgium) and were filled with either fast-disintegrating starch pellets (size $500-710 \mu \mathrm{m}, 753.7 \mathrm{mg}$ SD 12.6), consisting of $84.9 \%$ Uni-Pure EX starch (National starch Chemical Company, New Jersey, United States), 4.9\% Methocel E 15 (Colorcon, Dartford, Great Britain) and $10.2 \%$ sorbitol (Cerestar, Mechelen, Belgium), or with lyophilized powder (456.8 mg SD 5.8) consisting of 33.3\% lactose ( $\alpha$ Pharma, Braine L'Alleud, Belgium) and 66.6\% skimmed milk (Difco, Becton Dickinson, Erembodegem, Belgium). Both kinds of capsules were visually indistinguishable.

\subsection{Grading of Gram-stained vaginal smears}

The Gram-stained vaginal smears were scored by three independent assessors (GC, RV and GL) according to the criteria previously described [7]. Briefly, Gram-stained vaginal smears were categorized as grade I (normal) when only Lactobacillus cell types were present, as grade II (intermediate) when both Lactobacillus and bacterial vaginosis-associated cell types were present, as grade III (bacterial vaginosis) when bacterial vaginosis-associated cell types were abundant in the absence of lactobacilli, as grade IV when only Gram positive cocci were observed, as grade I-like when Gram positive rods either quite small and short or otherwise irregularly shaped with curved edges were predominant [7], and as grade 0 when no bacterial cells were present.

Grade I specimens were further subdivided into grade Ia specimens when only Lactobacillus crispatus cell types (plump, mostly short rods) were present, into grade Ib when only other Lactobacillus cell types were present (smaller or more elongated and less stained than in Ia smears) and into grade Iab when both $L$. crispatus and other lactobacilli were present. An additional Gram stain category, grade I-Polymorphonuclear neutrophils (I-PMN), was assigned to 'idiopathic purulent grade I' smears, i.e. smears showing heavy leukorrhea with PMN (i.e. more than 50 PMN per high power field (hpf)) in the presence of normal numbers of Lactobacillus spp., but in the absence of pathogens such as Candida spp. [8]. The number of PMN and of bare nuclei, resulting from cytolysis, was scored as low (less than 10 per hpf), intermediate (between 10 and 50 per hpf) or high (more than 50 per hpf) $[9,10]$. 

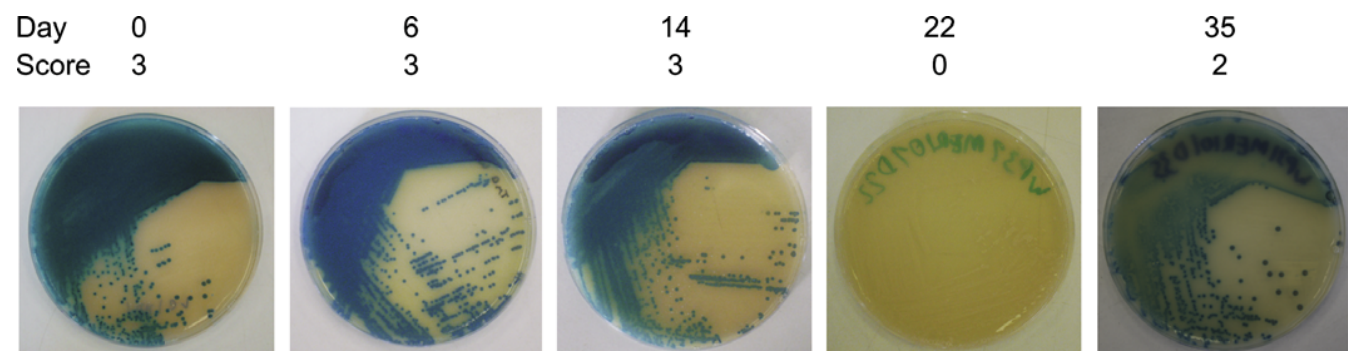

Fig. 1. $\mathrm{H}_{2} \mathrm{O}_{2}$ production of vaginal bacteria of volunteer P1 as measured by direct inoculation of $75 \mu$ l of the vaginal $\mathrm{E}$ swab medium on TMB ${ }^{\text {plus }}$ agar plates at each visit.

For the purpose of this study, grade I or Lactobacillus-dominated vaginal microflora is designated as 'normal vaginal microflora' and all other grades as 'abnormal vaginal microflora'.

\subsection{Hydrogen peroxide production}

The presence of vaginal microorganisms producing hydrogen peroxide was assessed by direct inoculation of $75 \mu \mathrm{l}$ of ESwab medium on TMB ${ }^{\text {lus }}$ agar plates [11]. After a 2 day incubation period at $37{ }^{\circ} \mathrm{C}$ in an anaerobic chamber (BugBox, LedTechno, Heusden-Zolder, Belgium), the plates were exposed to oxygen for $1.5 \mathrm{~h}$ and photographed. Each plate was given a score according to the intensity of the color: score 0 when no $\mathrm{H}_{2} \mathrm{O}_{2}$ was produced, score 1 for weak $\mathrm{H}_{2} \mathrm{O}_{2}$ production, score 2 for strong $\mathrm{H}_{2} \mathrm{O}_{2}$ production and score 3 for very strong $\mathrm{H}_{2} \mathrm{O}_{2}$ production (Fig. 1).

\section{Results}

Eighteen women on monophasic oral contraceptives (OC) were enrolled, whereby all continued taking OCs after the screening visit, but stopped after day 14 of enrollment to evoke a withdrawal bleeding. All women were randomized in three groups, i.e. group $\mathrm{P}$, administering capsules filled with starch-based pellets, group L, administering capsules filled with lyophilized powder or the control group (group C), not administering capsules. All women completed a diary, recording symptoms that occurred during the 6 -week study period. All women completed the study and adhered to the study protocol.

\subsection{Adverse events and adverse effects}

No adverse effects on the vaginal and ectocervical mucosa were observed throughout the study period, nor were any serious ad- verse events (SAE) reported by the study participants (Table 1 ). In the control group, three women did not report any adverse events (AEs), while three women reported one, two and four AEs, respectively (median of $0.5 \mathrm{AEs}$ per patient). In group $\mathrm{L}$, five out of six study participants reported at least one $\mathrm{AE}$, with a median of 1.5 AEs. Finally, in group P, all patients reported at least one $\mathrm{AE}$, with a median of $2.5 \mathrm{AEs}$ per patient. There was no significant difference in the occurrence of AEs between groups (Kruskal-Wallis $p=0.215$ ).

\subsection{Vaginal $p H$}

At screening, the pH was lower than 4.7 and thus normal for all but two volunteers who presented with an elevated $\mathrm{pH}$ due to the presence of menstrual blood (Fig. 2). Immediately after administration, at day 6, the vaginal $\mathrm{pH}$ was normal for all groups, except for one woman in group $\mathrm{P}$ with elevated $\mathrm{pH}$ (5.0), who also had a Gram-stained smear with few bacteria at screening and throughout the study period. While at day 14 , all $\mathrm{pH}$ values were normal, on day 22 , i.e. after withdrawal bleeding, mean $\mathrm{pH}$ increased in all groups. Respectively, three, two and two volunteers in group C, group P and group L had a pH higher than 4.7 (Fig. 2). At day 35 , all subjects, except one with residual blood loss, had a vaginal $\mathrm{pH}$ lower than or equal to 4.7 .

\subsection{Effect on microflora as assessed by Gram stain}

At screening, all subjects had a normal vaginal microflora (i.e. grade Ia, Ib or Iab) except for one in group P who had a smear almost devoid of bacteria and another one in group $L$ for whom the smear showed heavy leukorrhea with polymorphonuclear neutrophils (PMN) in the presence of normal numbers of Lactobacillus spp. (grade I-PMN) (Table 2).

Table 1

Reported adverse events.

\begin{tabular}{|c|c|c|c|c|c|c|}
\hline \multirow[t]{2}{*}{ Adverse event ${ }^{\mathrm{a}}$} & \multicolumn{3}{|c|}{ All adverse events } & \multicolumn{3}{|c|}{ Possibly drug-related adverse events } \\
\hline & Control group & Lyophilized powder & Starch pellets & Control group & Lyophilized powder & Starch pellets \\
\hline Pruritus vulvae & 1 & & 1 & & & \\
\hline Leukorrhea & & 3 & 2 & & 2 & 1 \\
\hline Vaginal discharge (Brownish) & & 1 & 1 & & 1 & 1 \\
\hline Vaginal bleeding/spotting & 1 & & 1 & & & 1 \\
\hline Abdominal pain & & 1 & 1 & & & \\
\hline Cervix pain & & & 1 & & & 1 \\
\hline Dysmenorrhoea & & 1 & & & & \\
\hline Headache & & 4 & & & & \\
\hline Nausea & & 1 & & & & \\
\hline Diarrhoea & 1 & & & & & \\
\hline Neck pain & 1 & & & & & \\
\hline Cold/sinusitis & 1 & 1 & & & & \\
\hline Toothache & 2 & & & & & \\
\hline Breast pain female & & 1 & & & & \\
\hline Erythema & & 1 & & & & \\
\hline Vaginal loss of 'powder' & & 2 & 2 & & 2 & 2 \\
\hline
\end{tabular}

a (1) Definitely not related, (2) probably not related, (3) possibly related, (4) probably related, (5) definitely related. 


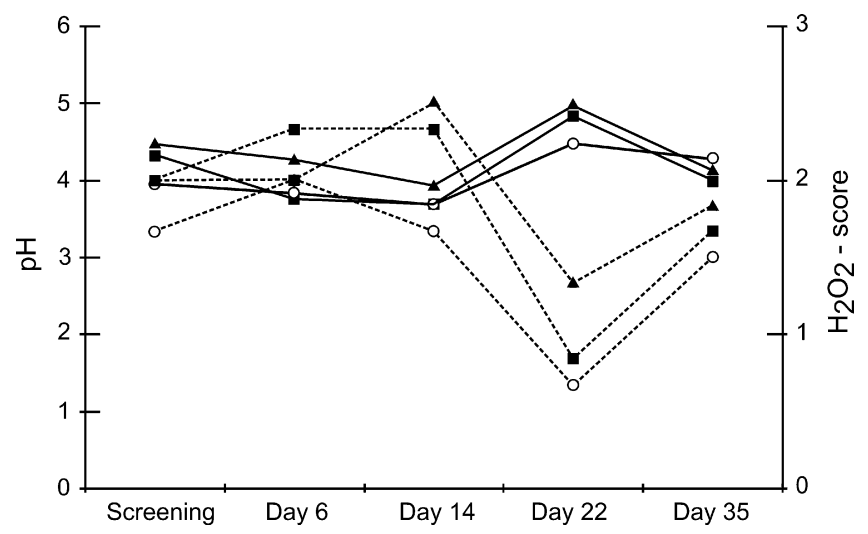

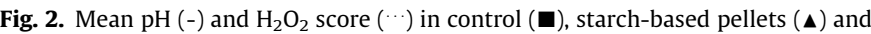
lyophilized powder (o) groups.

Immediately, following the withdrawal bleeding, four volunteers had an abnormal microflora, whereby three, i.e. two with grade II and with one grade III, belonged to the control group and one, with grade I-like smear, was from group P. At day 35, two volunteers from group $P$ presented with abnormal microflora while all other volunteers showed a normal microflora.

Although 11 of the 18 volunteers had PMN in the vaginal smear on at least one study visit, high levels of PMN were observed only in one woman at screening (Table 2). The number of women for whom PMN were present in the vaginal smear was highest in the control group at days 6 and 35 .

While high levels of bare nuclei were not found in any of the volunteers, a total of 13 of the 18 women had bare nuclei at least one study day (Table 2). Respectively, three, three and two women in groups $\mathrm{C}, \mathrm{L}$ and $\mathrm{P}$ presented with bare nuclei at screening. The number of women with bare nuclei was highest in group $\mathrm{C}$ (respectively, three, four, one and one at day 6, 14, 22 and 35). Both in group $\mathrm{P}$ and $\mathrm{L}$, one or two women were found to have intermediate or low levels of bare nuclei at all follow-up visits. All women with bare nuclei had a grade I microflora, and the bare nuclei were primarily present at a $\mathrm{pH}$ of 3.6, i.e. five of the nine women with bare nuclei had a pH of 3.6 at screening, five of seven at day 6 , all eight women at day 14, two of the four at day 22 and none of the three at day 35 . Among the total of 49 remaining samples for which no bare nuclei could be observed, $\mathrm{pH}$ values of 3.6 were observed only 15 times. Overall, there was a highly significant correlation $(p<0.001)$ between vaginal $\mathrm{pH}$ and the presence of bare nuclei. In particular, bare nuclei were associated with a lower median $\mathrm{pH}$ of 3.6 (interquartile range 3.6-4.1) as compared to a median $\mathrm{pH}$ of 4.1 (interquartile range 4.1-4.7) in samples not containing bare nuclei, indicating a higher correspondence of vaginal mucosal cytolysis with lower $\mathrm{pH}$.

\subsection{Hydrogen peroxide production}

$\mathrm{H}_{2} \mathrm{O}_{2}$ production was assessed by culture of the vaginal swab on $\mathrm{TMB}^{\text {plus }}$ agar plates (Fig. 1). $\mathrm{H}_{2} \mathrm{O}_{2}$ production scores of the vaginal microflora at day 35 were comparable with the scores at screening (Fig. 2).

At screening, at day 6 and at day 14, all women, but one in the control group, had a microflora comprising hydrogen peroxideproducing lactobacilli based on color production on $\mathrm{TMB}^{\text {plus }}$ agar plates. Although immediately after the withdrawal bleeding at day 22, there was a decrease in $\mathrm{H}_{2} \mathrm{O}_{2}$ scores in all but two women, $\mathrm{H}_{2} \mathrm{O}_{2}$ production was restored in every single subject at midcycle, even in the five women who completely lacked hydrogen peroxide-producing lactobacilli immediately after withdrawal bleeding.

\section{Discussion}

Among 18 volunteers who participated in this study, aimed at comparing the effect of starch-based and lyophilized lactose/ skimmed milk carriers of probiotic formulations on the vaginal $\mathrm{pH}$ and microflora and studying possible adverse effects and events, we found that 16 out of 18 women showed the same cyclic variation in $\mathrm{pH}$ and Gram stain. Although immediately after withdrawal bleeding, 8 out of 18 women had either an elevated $\mathrm{pH}$ $(<4.7)$, a disturbed microflora or lacked hydrogen peroxide-producing lactobacilli, at midcycle all had hydrogen peroxide-producing lactobacilli and a normal $\mathrm{pH}$ ( $\mathrm{pH}$ between 3.6 and 4.7), and all but two women from group P had a normal Gram stain.

Table 2

Gram staining, bare nuclei and $\mathrm{pH}$ results for the six subjects of each of the three groups.

\begin{tabular}{|c|c|c|c|c|c|c|c|c|c|c|c|c|c|c|c|}
\hline \multirow[t]{2}{*}{ Subject $^{\mathrm{a}}$} & \multicolumn{3}{|c|}{ Screening } & \multicolumn{3}{|l|}{ Day 6} & \multicolumn{3}{|c|}{ Day 14} & \multicolumn{3}{|l|}{ Day 22} & \multicolumn{3}{|c|}{ Day 35} \\
\hline & Grade $^{b}$ & $\mathrm{BN}^{\mathrm{c}}$ & $\mathrm{pH}$ & Grade & $\mathrm{BN}$ & $\mathrm{pH}$ & Grade & $\mathrm{BN}$ & $\mathrm{pH}$ & Grade & $\mathrm{BN}$ & $\mathrm{pH}$ & Grade & $\mathrm{BN}$ & $\mathrm{pH}$ \\
\hline $\mathrm{C} 1$ & Ia & - & 4.1 & Ia & ++ & 3.6 & Ia & ++ & 3.6 & Ia & - & 3.6 & Ia & - & 4.0 \\
\hline $\mathrm{C} 2$ & Ia & + & 4.1 & Ia & - & 3.6 & Ia & + & 3.6 & Ia & + & 3.6 & Ia & - & 4.1 \\
\hline $\mathrm{C} 3$ & Ia & + & 3.6 & Ia & + & 3.6 & Ia & + & 3.6 & Ia & - & 3.6 & Ia & + & 4.1 \\
\hline C4 & $\mathrm{Ib}$ & - & 4.1 & Ia & - & 4.1 & Ia & - & 4.1 & II & - & 6.1 & Ia & - & 4.1 \\
\hline C5 & Iab & - & $>6.1$ & $\mathrm{Ib}$ & - & 4.1 & $\mathrm{Ib}$ & - & 3.6 & III & - & 5.6 & Ia & - & 4.1 \\
\hline C6 & Ia & + & 4.0 & Ia & + & 3.6 & Ia & + & 3.6 & II & - & $>6.5$ & Ia & - & 3.6 \\
\hline P1 & $\mathrm{Ib}$ & - & 4.7 & $\mathrm{Ib}$ & - & 4.7 & $\mathrm{Ib}$ & - & 4.1 & I-like & - & 6.1 & I-like & - & 4.1 \\
\hline P2 & Ia & + & 3.6 & Ia & + & 4.1 & Ia & + & 3.6 & Iab & + & 4.1 & Ia & ++ & 4.1 \\
\hline P3 & $\mathrm{Ib}$ & - & 4.1 & $\mathrm{Ib}$ & - & 4.1 & $\mathrm{Ib}$ & - & 4.1 & $\mathrm{Ib}$ & + & 4.7 & $\mathrm{Ib}$ & - & 4.1 \\
\hline P4 & Ia & - & 4.7 & Ia & - & 5.0 & Ia & - & 4.1 & 0 & - & 5.8 & Ia & - & 4.4 \\
\hline P5 & Ia & ++ & 3.6 & Ia & + & 3.6 & Ia & ++ & 3.6 & Iab & - & 4.7 & Iab & - & 3.6 \\
\hline P6 & $\mathrm{Ib}$ & - & $>6.1$ & $\mathrm{Ib}$ & - & 4.1 & $\mathrm{Ib}$ & - & 4.1 & $\mathrm{Ib}$ & - & 4.4 & III & - & 4.4 \\
\hline L1 & $\mathrm{Ib}$ & - & 4.1 & $\mathrm{Ib}$ & - & 3.6 & Iab & + & 3.6 & Iab & + & 3.6 & Iab & - & 3.6 \\
\hline L2 & Ib & + & 4.7 & Ib & - & 4.1 & Iab & - & 4.1 & Ia & - & 4.4 & $\mathrm{Ib}$ & - & 5.0 \\
\hline L3 & Ia-PMN & - & 3.6 & Ia & + & 4.1 & Ia & + & 3.6 & Ia & - & 4.7 & Ia & ++ & 4.4 \\
\hline L4 & Ia & + & 4.1 & Ia & - & 4.0 & Ia & - & 3.6 & Ia & - & 5.6 & Ia & - & 4.7 \\
\hline L5 & Ia & + & 3.6 & Ia & - & 3.6 & Iab & - & 3.6 & Ia & - & 3.6 & Ia & - & 4.4 \\
\hline L6 & Ia & + & 3.6 & Ia & + & 3.6 & Ia & - & 3.6 & $\mathrm{Ib}$ & - & 5.0 & Iab & - & 3.6 \\
\hline
\end{tabular}

${ }^{a}$ C: control group: no administration, P: group with administration of starch pellets, L: group with administration of lyophilized powder

b Gram stain scoring according to Claeys criteria [7,8].

c Presence of bare nuclei (BN): no bare nuclei: -, low quantity of bare nuclei (less than 10 per hpf): +, intermediate quantity of bare nuclei (between 10 and 50 per hpf): ++. 
The data show that, immediately after withdrawal bleeding, no Gram stain-based changes in microflora could be observed in group $\mathrm{L}$, in contrast to the control group and group $\mathrm{P}$, although the drop in $\mathrm{H}_{2} \mathrm{O}_{2}$ production and the raise in $\mathrm{pH}$ were comparable to both other groups. This observation tends to confirm the finding that lyophilized skimmed milk and lactose, even when applied vaginally on their own, can alter the vaginal microflora by stimulating the growth of lactobacilli [12]. Because this study comprises only 18 women randomized to three different groups, this observation lacks statistical power.

Although we found a high number of samples (31 out of 80 ) with the presence of bare nuclei, this could not be related to the administration of the formulations, since most women with bare nuclei were observed in the control group. An abundant growth of vaginal lactobacilli in combination with the presence of bare nuclei is known as cytolytic vaginosis $[9,13,14]$. The underlying mechanisms remain elusive. The condition is characterized by a very low $\mathrm{pH}(3.5-4.5)$ and this excessive acidity is thought to be toxic for the vaginal environment thereby leading to cytolysis of the vaginal epithelial cells $[9,15,16]$. Also, in this study, we found a significant correlation between the presence of bare nuclei and low $\mathrm{pH}$, i.e. 20 of 31 vaginal samples with bare nuclei had a $\mathrm{pH}$ of 3.6, compared to 15 of 49 vaginal samples without bare nuclei. Consequently, on microscopic examination, lactobacilli are observed along with fragmented or lysed epithelial cells with bare nuclei and cellular debris. In this study, 26 of the 31 vaginal samples with bare nuclei were characterized by grade Ia microflora, 3 out of 31 and 2 out of 31 vaginal samples with bare nuclei were characterized by grade Iab and grade $\mathrm{Ib}$, respectively.

Vaginal symptoms in group P included cervical pain, brownish vaginal discharge and spotting and were presumably procedurerelated following speculum examination. Also, brownish vaginal discharge reported by women in group L was likely to be investigational procedure related and the only AEs that were considered as possibly drug related were whitish discharge as this consistently reflected loss of powder. Whereas both vaginal drug delivery forms appear to be safe, it has be to be acknowledged that these vehicles may cause some transient discomfort through increased vaginal discharge as is also observed with established vaginal delivery forms such as creams, gels and ovules and with vaginal Lactobacillus capsules [17].

Various studies have been performed to assess the acceptability, safety and effectiveness of vaginal Lactobacillus formulations [1722]. Although in general, there were no significant differences in the severity, nature and frequency of adverse events between the intervention and the placebo group, a phase I, placebo-controlled trial for the prevention of recurrent urinary tract infection by the use of L. crispatus CTV-05 suppositories suggested that vaginal installation of these capsules can induce a mild inflammatory response in the bladder or vaginal mucosa in some subjects without causing prolonged urogenital infection [18]. In this study, using colposcopy, neither inflammatory signs nor any mucosal lesions were observed in the three study groups.

\section{Conclusions}

No adverse events other than loss of whitish discharge were reported, and all major changes in the status of the microflora and $\mathrm{pH}$ value occurred immediately after the withdrawal bleeding, a period that is characterized by disturbance of the vaginal microflora and a decrease in hydrogen peroxide-producing strains $[23,24]$. As such, we can conclude that the changes were due to withdrawal bleeding and were not related to treatment, indicating that fast-disintegrating starch pellets and lyophilized lactose/ skimmed milk are acceptable carrier materials for the vaginal delivery of probiotic strains or other drugs.

\section{Disclosure statement}

No competing financial interests exist.

\section{Acknowledgment}

This study was funded by a Grant from the Institute for the Promotion of Innovation by Science and Technology (IWT), Flanders, Belgium.

\section{References}

[1] D.A. Eschenbach, S. Hillier, C. Critchlow, et al., Diagnosis and clinical manifestations of bacterial vaginosis, Am. J. Obstet. Gynecol. 158 (4) (1988) 819-828.

[2] H. Leitich, M. Brunbauer, B. Bodner-Adler, et al., Antibiotic treatment of bacterial vaginosis in pregnancy: a meta-analysis, Am. J. Obstet. Gynecol. 188 (3) (2003) 752-758.

[3] G. Reid, The scientific basis for probiotic strains of Lactobacillus, Appl. Environ. Microbiol. 65 (9) (1999) 3763-3766.

[4] M.N. Austin, R.H. Beigi, L.A. Meyn, S.L. Hillier, Microbiologic response to treatment of bacterial vaginosis with topical clindamycin or metronidazole, J. Clin. Microbiol. 43 (9) (2005) 4492-4497.

[5] G. Zarate, M.S. Tomas, M.E. Nader-Macias, Effect of some pharmaceutical excipients on the survival of probiotic vaginal lactobacilli, Can. J. Microbiol. 51 (6) (2005) 483-489.

[6] N. Poelvoorde, H. Verstraelen, R Verhelst, et al., In vivo evaluation of the vaginal distribution and retention of a multi-particulate pellet formulation, Eur. J. Pharm. Biopharm., in press.

[7] R. Verhelst, H. Verstraelen, G. Claeys, et al., Comparison between Gram stain and culture for the characterization of vaginal microflora: definition of a distinct grade that resembles grade I microflora and revised categorization of grade I microflora, BMC Microbiol. 5 (2005) 61.

[8] H. Verstraelen, R. Verhelst, K. Roelens, et al., Modified classification of Gramstained vaginal smears to predict spontaneous preterm birth: a prospective cohort study, Am. J. Obstet. Gynecol. 196 (6) (2007) 528 (pp. e521-e526).

[9] L.J. Cibley, Cytolytic vaginosis, Am. J. Obstet. Gynecol. 165 (4 Pt 2) (1991) 1245-1249.

[10] G.G. Donders, Gram stain method shows better sensitivity than clinical criteria for detection of bacterial vaginosis in surveillance of pregnant, low-income women in a clinical setting, Infect. Dis. Obstet. Gynecol. 7 (6) (1999) 273-275.

[11] L.K. Rabe, S.L. Hillier, Optimization of media for detection of hydrogen peroxide production by Lactobacillus species, J. Clin. Microbiol. 41 (7) (2003) 3260-3264.

[12] G. Reid, F. Soboh, A.W. Bruce, M. Mittelman, Effect of nutrient composition on the in vitro growth of urogenital lactobacilli and uropathogens, Can. J. Microbiol. 44 (9) (1998) 866-871.

[13] C. Pahlson, P.G. Larsson, The ecologically wrong vaginal lactobacilli, Med. Hypotheses 36 (2) (1991) 126-130.

[14] P. Korenek, R. Britton, C. Hawkins, Differentiation of the vaginoses-bacterial vaginosis, Lactobacillosis, and Cytolytic vaginosis, Internet J. Adv. Nursing Pract. 6 (1) (2003).

[15] K. Nasielli, J. Dudkiewicz, M. Nasiell, A. Hjerpe, C. Silfversward, The occurrence of Bacillus vaginalis Doderlein and cytolysis in dysplasia, carcinoma in situ, and invasive carcinoma of the uterine cervix, Acta Cytol. 16 (1) (1972) 21-25.

[16] G.G. Donders, Microscopy of the bacterial flora on fresh vaginal smears, Infect. Dis. Obstet. Gynecol. 7 (3) (1999) 126-127.

[17] J.M. Marrazzo, R.L. Cook, H.C. Wiesenfeld, et al., Women's satisfaction with an intravaginal Lactobacillus capsule for the treatment of bacterial vaginosis, J. Womens Health (Larchmt) 15 (9) (2006) 1053-1060.

[18] C.A. Czaja, A.E. Stapleton, Y. Yarova-Yarovaya, W.E. Stamm, Phase I trial of a Lactobacillus crispatus vaginal suppository for prevention of recurrent urinary tract infection in women, Infect. Dis. Obstet. Gynecol. 2007 (2007) 35387.

[19] S. Uehara, K. Monden, K. Nomoto, et al., A pilot study evaluating the safety and effectiveness of Lactobacillus vaginal suppositories in patients with recurrent urinary tract infection, Int. J. Antimicrob. Agents 28 (Suppl. 1) (2006) 30-34.

[20] P.G. Larsson, B. Stray-Pedersen, K.R. Ryttig, S. Larsen, Human lactobacilli as supplementation of clindamycin to patients with bacterial vaginosis reduce the recurrence rate; a 6 -month, double-blind, randomized, placebo-controlled study, BMC Womens Health 8 (2008) 3.

[21] L. Petricevic, A. Witt, The role of Lactobacillus casei rhamnosus Lcr35 in restoring the normal vaginal flora after antibiotic treatment of bacterial vaginosis, BJOG 115 (11) (2008) 1369-1374.

[22] K. Eriksson, B. Carlsson, U. Forsum, P.G. Larsson, A double-blind treatment study of bacterial vaginosis with normal vaginal lactobacilli after an open treatment with vaginal clindamycin ovules, Acta Derm. Venereol. 85 (1)(2005) 42-46.

[23] F.E. Keane, C.A. Ison, D. Taylor-Robinson, A longitudinal study of the vaginal flora over a menstrual cycle, Int. J. STD AIDS 8 (8) (1997) 489-494.

[24] D.A. Eschenbach, S.S. Thwin, D.L. Patton, et al., Influence of the normal menstrual cycle on vaginal tissue, discharge, and microflora, Clin. Infect. Dis. 30 (6) (2000) 901-907. 